\title{
無尾翼・小型羽ばたき飛翔体の安定性とその姿勢制御 Flight Stability and Body Angle Control of a Micro Flapping Robot
}

\author{
O正 井村忠継（九工大院） 正 㴊脇正樹（九工大） 正 田中和博 (九工大)

\begin{abstract}
Tadatsugu Imura, Kyushu Institute of Technology, 680-4 Kawazu, lizuka, Fukuoka Masaki Fuchiwaki, Kyushu Institute of Technology, 680-4 Kawazu, lizuka, Fukuoka Kazuhiro Tanaka, Kyushu Institute of Technology, 680-4 Kawazu, Iizuka, Fukuoka
\end{abstract}

\begin{abstract}
Micro-Air-Vehicle (MAV) using insect and bird flight mechanisms have been researching all over the world in recent years since the micro-electro-mechanical systems (MEMS) have been developed. Many researchers have developed MAV with various actuators and devices however their MAV have not been put to practical use yet. The purpose is clarifying the flight trajectory of micro flapping robot at different flapping frequencies. The micro flapping robot moves upward in high flapping frequency flight and moves downward in low flapping frequency flight. The flapping frequency of micro flapping robot on a flight is one of important parameter for the flight attitude control.
\end{abstract}

Key Words: Micro Air Vehicle, Tailless aircraft, Flapping frequency

\section{1. 緒言}

近年，橋梁や高層ビルの保守・点検作業や災害地での捜 索・救難支援など様々な利用が考えられている小型羽ばたき 飛翔体や MAV （Micro Air Vehicle）の研究が国内外を問わ ず活発に行われている(1). 羽ばたき飛翔体の特性の一つに, 連続的かつ非線形な羽ばたき運動のために従来の飛翔体に おいて要求される力およびモーメントの平衡点が特定でき ないことが挙げられる ${ }^{(2)}$.この特性のために直感的なデザイ ンや試行錯誤に基づく羽ばたき飛翔体が多く開発されてい る.世界中で開発された羽ばたき飛翔体は尾翼を用いて機体 の制御を行うなど, 姿勢角の安定の確保および機体の制御の ために複雑な構造を持つ必要があるため, 機体重量の増加が 問題視されている.

羽ばたき飛翔体の開発の手法として鳥や昆虫の飛翔を応 用することにより，小型・軽量でシンプルな構造を持ち，さ らには環境に溶け込むような飛翔を行う飛翔体を作り出せ ることが考えられる.この手法を用いて様々なアクチュエー タおよびデバイスを用いた小型羽ばたき飛翔体の開発が試 みられている，最近では，蝶の翅を模倣した翅を用いたBTO (Butterfly- type Ornithopter) の研究も報告されている ${ }^{(3)}$.また, Tanakaらは, BTOまわりの流れの可視化を通じて, 羽ばたき 運動と同期した迎角の受動的な変化が翅へのLeading edge vortexの安定的な付着を生むことにより飛翔を実現している ことを明らかにしている( ${ }^{(4)}$. さらには, 飛翔時の翅の変形に 着目し，翅の変形が異なるBTO を比較することにより，蝶 の翅脈が持つ影響を明らかにしている(3). Zaeem らは昆虫や 八チドリが持つ Traverse bending に着目し，弾性体を用いた 羽ばたきメカニズムを用いることにより，大きなフラッピン グ角および高い羽ばたき周波数を実現できることを明らか にしている(5).しかしながら，これらは実用化に至っていな いのが現状であり, その原因の 1 つに昆虫や鳥の飛翔メカニ ズムが十分に明らかにされていないことが挙げられる。

本研究では，蝶の羽ばたき特性を応用した無尾翼・小型羽 ばたき飛翔体 (Micro Flapping Robot) の羽ばたき周波数とそ の飛翔の関倸を明らかにすることを目的とする。具体的には， 姿勢角が安定するために必要な飛翔距離を調べ, 姿勢角が安 定した状態において羽ばたき周波数を変化させた際の飛翔 時の軌跡を導出し, 評価する。

\section{2. 無尾翼・小型羽ばたき飛翔体および実験方法}

図 1 に無尾翼・小型羽ばたき飛翔体を示す. 飛翔体の翅ス

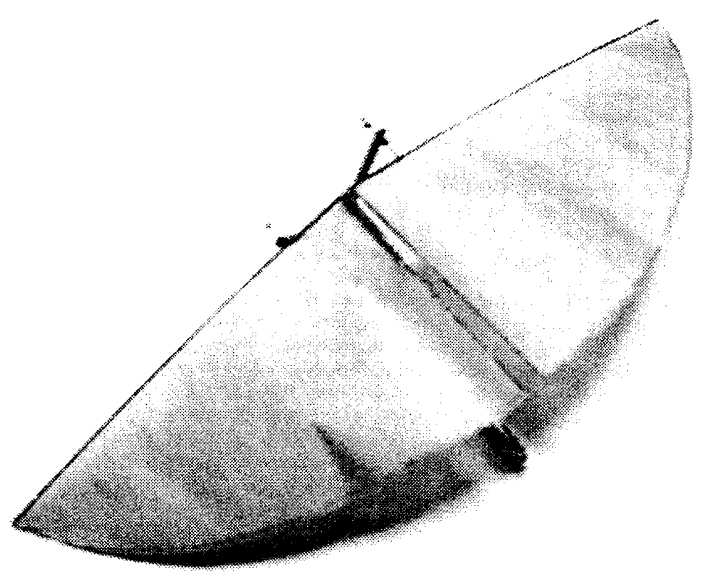

Fig. 1 Micro flapping robot

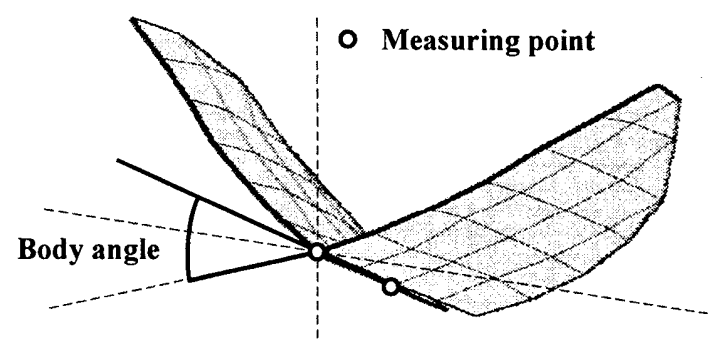

Fig. 2 Definition of body angle and measuring points

パン長さ, 翅䓋長さ, 重量, 翼面荷重, 羽ばたき周波数およ びアスペクト比はそれぞれ，240[ mm ], $80[\mathrm{~mm}], 1.97[\mathrm{~g}]$, $1.5\left[\mathrm{~N} / \mathrm{m}^{2}\right], 9-11[\mathrm{~Hz}]$ 程度および 3.0 である. 蝶の翼面荷重, 羽ばたき周波数およびアスペクト比はそれぞれ，0.5－4 [ W/m $\left.\mathrm{m}^{2}\right], 4-20[\mathrm{~Hz}]$ および $1.5-4.0$ である(6)ことから蝶に 近いサイズの飛翔体であるといえる.

無尾翼・小型羽ばたき飛翔体の飛翔の様子を撮影速度 500 [fps]のハイスピードカメラで撮影した。撮影した映像の画像 計測により，飛翔体の胴体部先端および後端の位置を計測し， 
垂直方向の速度および姿勢角を算出した（図 2)。さらには， 羽ばたき周波数が $11.0[\mathrm{~Hz}], 10.5[\mathrm{~Hz}], 10.0[\mathrm{~Hz}], 9.5[\mathrm{~Hz}]$ お よび $9.0[\mathrm{~Hz}]$ のときの飛翔軌跡を算出した.

\section{3、実験結果および考察}

3-1 無尾翼・小型羽ばたき飛翔体の安定性 図 3 に無 尾翼・小型羽ばたき飛翔体の飛翔時の飛翔速度および姿勢角 を示す. 図 3 の横軸，上段の縌軸および下段の縦軸はそれぞ れ，水平方向の位置，垂直方向の速度および姿勢角を示す. また, 図 3 の(a), (b), (c) および (d) はそれぞれ, 飛翔開始点, 姿勢角が 0 [deg.] の点，姿勢角が最大值 46 [deg.] を示す点 および姿勢角が安定したと考えられる一定の振幅および周 波数で姿勢角が振動し始めた点を示している.

飛翔開始直後 (a) において, 飛翔体の垂直方向の速度, 姿 勢角および姿勢角の角速度は負を示し，下向きに飛翔する。 飛翔の経過に伴い，姿勢角および姿勢角の角速度は大きくな り，姿勢角は正となる (b)．姿勢角が大きくなるに従い垂直 方向の速度も増加し, 姿勢角が正となった直後に垂直方向の 速度も正となる. また，その後バッテリ電圧が低下するまで, 常に垂直方向の飛翔速度は正となることを確認している. そ の結果，飛翔体はバッテリ電圧が低下するまで飛翔し，およ そ 20 分間飛翔を続ける. 姿勢角が正となった後, (c) におい て最大值を示すまで姿勢角は大きくなり続ける. 姿勢角が最 大值を示す $(\mathrm{c})$ 付近で飛翔速度は $0[\mathrm{~m} / \mathrm{s}]$ 程度まで減少する. また，このとき水平方向の速度も最小值となり，飛翔体の飛 翔速度は最も低くなる. 羽ばたき飛翔体は, 重力, 慣性力お よび流体力が平衡することにより，飛翔すると考えられてい る $^{(2)}$ 。これらのことから，飛翔速度の低下により飛翔体に 生じる推進力および揚力が変化し, 飛翔体に生じる力および モーメントの平衡点が変化した結果, 姿勢角を維持できなく なったと考えられる．姿勢角が最大值となった後，姿勢角は 小さくなり，姿勢角の振動は収束し，(d)において飛翔体の 姿勢角はほぼ一定の振幅および周波数で飛翔することから 姿勢角が安定していると考えられる. その際, 飛翔速度は増 加し $0[\mathrm{~m} / \mathrm{s}]$ から $1[\mathrm{~m} / \mathrm{s}]$ の間で振動する.また, 飛翔速度 は常に正を示すことから, 安定した姿勢角で飛翔高度が上昇 し続けることがわかる。これらのことから，無尾翼・小型羽 ばたき飛翔体は飛翔速度および姿勢角が増減した後, 安定し た姿勢角および常に正の垂直方向の速度で飛翔することが 分かった. さらには, 姿勢角が安定するまで $3[\mathrm{~m}]$ 程度飛翔 する必要があることが分かった。

$3-2$ 羽ばたき周波数と飛翔の関俰 図 4 に無尾翼・小 型羽ばたき飛翔体の姿勢角が安定すると考えられる水平方 向の位置が $3[\mathrm{~m}]$ から 4 [m] の範囲における羽ばたき周波数 が $9.5[\mathrm{~Hz}], 9.0[\mathrm{~Hz}]$ および $9.5[\mathrm{~Hz}]$ のときの飛翔軌跡を示す.

羽ばたき周波数が $11.0[\mathrm{~Hz}]$ および $10.5[\mathrm{~Hz}]$ のとき飛 翔体の飛翔高度は上昇し，10.0 [Hz] のとき飛翔高度を維持 し, $9.5[\mathrm{~Hz}]$ および $9.0[\mathrm{~Hz}]$ のとき飛翔高度が低下すること がわかる。 また，羽ばたき周波数が低下すると飛翔高度の上 昇の勾配が小さくなることも分かる. 羽ばたき周波数により， 飛翔体の翅に生じる揚力および推進力が変化することが知 られている(1)。また, 蝶やトンボなどは飛翔時に渦輪を形成 しながら飛翔することが知られている(7).このことから無尾 翼・小型羽ばたき飛翔体も蝶やトンボなどの昆虫と同様に羽 ばたき運動によって渦輪を形成することがわかる。これらの ことから, 羽ばたき周波数が上昇することにより翅の運動速 度が高くなり, 翅が形成する渦輪が強く発達するため大きな 揚力および推進力が生じ, 羽ばたき周波数が低いとき, 翅が 形成する渦輪が弱く発達するため小さな揚力および推進力 が生じると考えられる。飛翔する無星翼・小型羽ばたき飛翔 体の羽ばたき周波数が高いとき飛翔高度は上昇し, 低いとき 飛翔高度は低下寸る。 また, 羽ばたき周波数を変化させた場

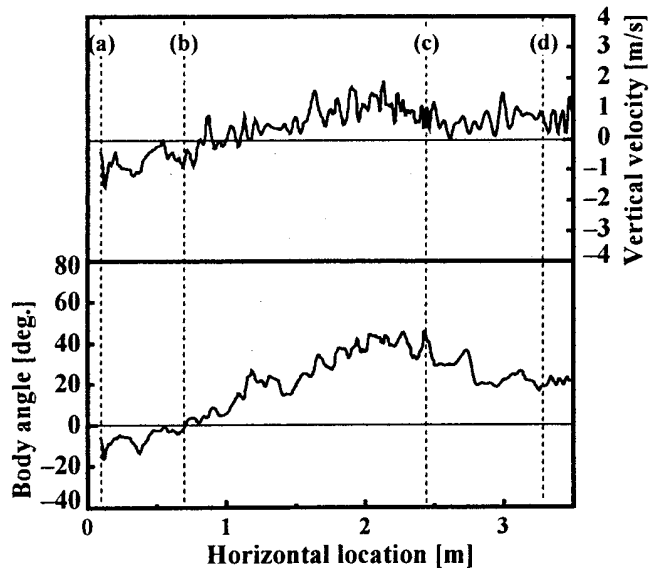

Fig. 3 Body angle and vertical velocity on free flight

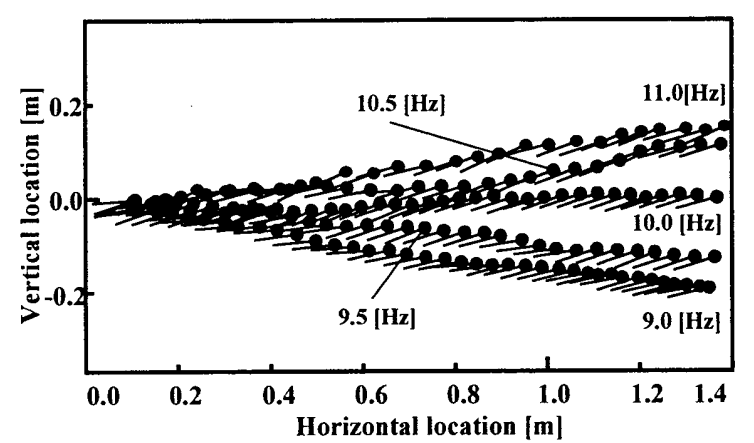

Fig. 4 Flight trajectories at different flapping frequencies

合においても，飛翔体は飛翔することから，尾翼を持たない 羽ばたき飛翔体においても羽ばたき周波数を用いて飛翔高 度を制御できると考えられる。

\section{4. 結論}

飛翔する無尾翼・小型羽ばたき飛翔体の姿勢角は, 飛翔開 始直後おいて微小に振動しつつ姿勢角は増減するものの， 3 [m] 程度飛翔した後, 安定することが分かった。姿勢角が安 定すると思われる飛翔開始点から $3[\mathrm{~m}]$ ほど飛翔した位置 において，尾翼を持たない羽ばたき飛翔体においても，羽ば たき周波数が高いときは, 飛翔体の飛翔高度は上昇する. 羽 ばたき周波数が低いときは, 飛翔時の飛翔高度は低下するこ とが明らかとなった。これらのことから, 羽ばたき周波数を 変化させることにより, 飛翔時の飛翔高度は変化するといえ る.さらには，羽ばたき周波数は，無尾翼・小型羽ばたき飛 翔体の飛翔高度の制御に重要なパラメータの1つと考えられ る.

\section{参考文献}

1. Lung-Jieh Yang et al., Sensors and Actuators A, 139, pp. 95-103, 2007

2. A. T. Pfeiffer et al., J. Bio. Eng., vol. 7, pp. 102-111, 2010

3. Tanaka H., et al., IEEE / RSJ International Conference on Intelligent Robots and Systems (2008), pp. 3095-3100

4. 田中博人5, 日本機械学会論文集 B 編, 718, (2007), 1490-1496

5. Zaeem A. Khan et al., Proceedings of the 2006 IEEE International Conference on Robotics and Automation Orlando, Florida - May 2006

6. 東 昭, 生物の動きの辞典 (1997)

7. R. J. Bomphrey, Exp. Fluids, Vol. 40., pp. 546-554, 2006 